\title{
Preparation and 3D Morphology Observation of Phenolic Resin-Silica Nanocomposites
}

\author{
M. Z. Norul Azlin and M. Z. Siti Zuraifah
}

\begin{abstract}
Phenolic resin-silica nanocomposites samples in pellet shape have been successfully prepared by intercalation of polymer solution through the hot pressing method. The phenolic resin is modified with organic elastomers of silica nanoparticles, which is about 20 nanometer in diameter. The X-Ray Microtomogaphy (XRM) topographies have shown that the porosity exists on fracture structure for each nanocomposite. The nanocomposites surface structure has been analyzed using Scanning Electron Microscope (SEM). The observation shows that the fracture surface of the pure phenolic resin is relatively smooth and glassy, which is typical for a brittle material, but the phenolic resin-silica composites fracture surface is not smooth at all. The observations indicate the pure phenolic resin is brittle than phenolic resin-silica nanocomposites.
\end{abstract}

Index Terms-Phenolic resin, silica content, nanocomposites, structure.

\section{INTRODUCTION}

Phenolic resins (PR) have been widely used as coatings and adhesives composites composites, due to their excellent flame resistance, heat resistance, insulativity, dimensional stability and chemical resistance matrices of fibre-reinforced composites materials, unique applications in commercial sectors, coating, laminates and composites, aeronautical and aerospace construction, for rocket nozzles, disk brakes and thermal insulating components [1]-[6]. However, their application has significantly been limited by inherent brittleness with a poor resistance to crack initiation and growth [1], [2].

Materials used as toughening agents of PR include elastomers such as natural rubber and nitrile butadiene rubber (NBR), reactive liquid polymers such as liquid nitrile butadiene and carboxyl terminated butadiene acrylonitrile (CTBN), plastics and such as polysulfone and polyamide, oils such as cashew nut shell liquid, tung oil and linseed oil, and fibers such as glass fibers and Aramid fibers. The most widely used toughening agents are elastomers due to their high efficiency and low cost, inorganic particles such as silica.

In recent years, polymer/layered silicate (PLS) nanocomposites have attracted great interest, both in industry and in academia, because they often exhibit

Manuscript received November 19, 2012; revised February 20, 2013.

M. Z. Norul Azlin is with Centre of Preparatory and General Studies with the Terengganu Advanced Technical Institute University College (TATI University College), Jalan Panchor, Telok Kalong, 24000 Kemaman, Terengganu, Malaysia (e-mail: norulazlin@tatiuc.edu.my).

M. Z. Siti Zuraifah is with Faculty of Manufacturing Engineering Technology, Terengganu Advanced Technical Institute University College (TATI University College), Jalan Panchor, Telok Kalong, 24000 Kemaman, Terengganu, Malaysia (e-mail: zuraifah@tatiuc.edu.my). remarkable improvement in materials properties when compared with virgin polymer or conventional micro- and macro-composites. These improvements include high modulus, increased strength and heat resistance, decreased gas permeability and flammability and increased biodegradability of biodegradable polymers. On the other hand, there has been considerable interest in theory and simulations addressing the preparation and properties of these materials and they are also considered to be unique model systems to study the structure and dynamics of polymers in confined environments [7]. Based on the above discussion, there is no doubt that layered silicate (inorganic polymer) has a very high potential to improve phenolic resin applications. Hence, this research is aimed to investigate the properties and structure of phenolic resin modification by addition of layered silicate.

\section{MATERIALS AND METHOD}

The silica content contained 51 wt. $\%$ of distilled water, 25 wt.\% of ethanol, 23 wt.\% silicates and 1 wt.\% of hydrochloride acid. The solution was stirred continuously at room temperature for 1 hour in a beaker. The mixtures were dried for 1day at room temperature. Following the above procedure, silicate solution were prepared and then mixed according to the desired weight ratio with phenolic resin composites to prepare the silicate layered on the phenolic resin composite. Micro tomography $(\mu \mathrm{CT})$, a nondestructive $3 \mathrm{D}$ imaging technique has been used to determine the intensity of content at each voxel and porosity for each nanocomposites sample. Sky Scan micro tomography is available in a range of easy to use desktop instruments, which generate 3D images of the samples morphology and internal microstructure with resolution down to the sub-micron level. The micro focus X-ray source was set to $103 \mathrm{kV}$ and $96 \mathrm{~A}$. The nanocomposites samples scanned at a $13.0 \mu \mathrm{m}$ resolution with an integration time 18 minutes. After completion of the $\mathrm{x}-\mathrm{y}$ scan, slices were reconstructed and analyzed using the manufactures complete imaging and evaluation solution software. Scanning Electron Microscope (SEM) investigations were used to examine structure of the phenolic resin-silica nanocomposites sample. Nanocomposites will be placed on alumina plat and was sputter coated with a thin gold layer under vacuum environment. This is done to prevent the accumulation of static electric fields at the specimen due to the electron irradiation during imaging.

\section{RESULTS AND DISCUSSION}

The electronic signal, sent by the camera to the monitor, 
is transformed in digital sign. That sign is illustrated in Figure 1a-e processed in real time by a computer and presented in a video monitor, being stored under the file form.

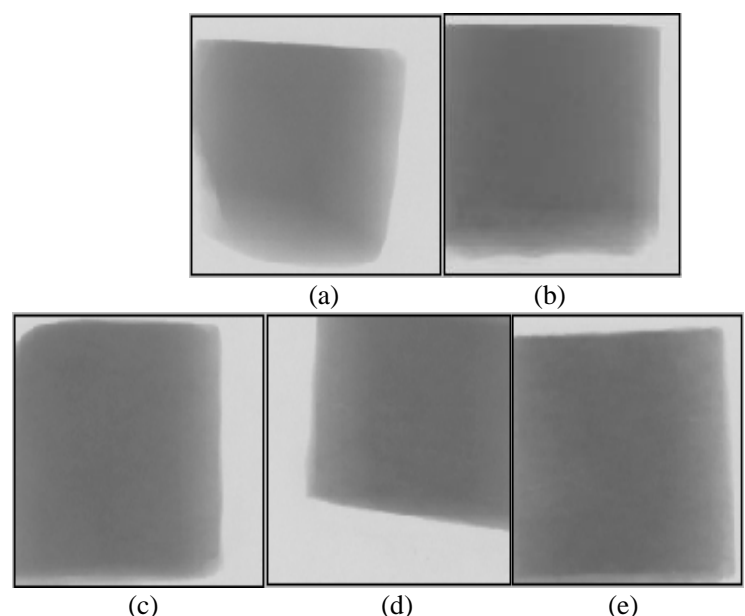

Fig. 1. Processed in real time of nanocomposites samples (a) P100S0, (b) P90S10, (c) P80S20, (d) P70S30 and (e) P60S40

With the digital sign, the process of the reconstructing begins are presented in Fig. 2 a-e.

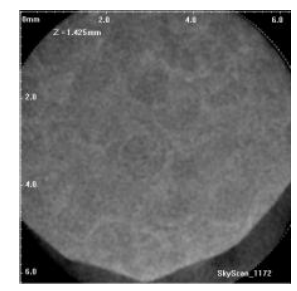

(a)

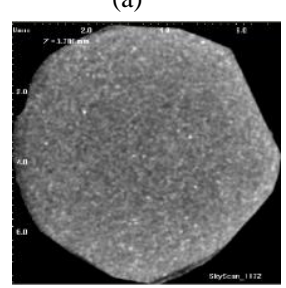

(c)

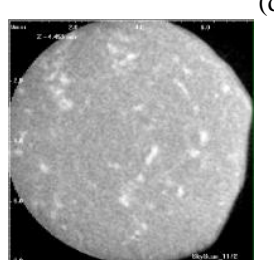

(e)

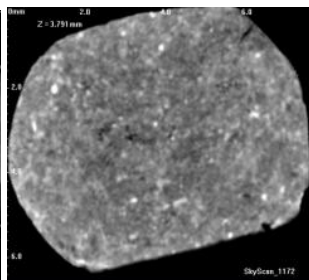

(b)

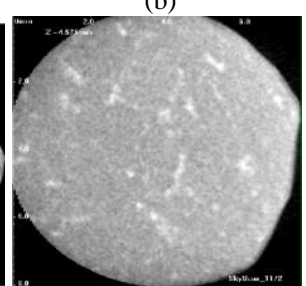

(d)
Fig. 2. The 2D reconstruction for nanocomposites sample (a) P100S0, (b) P90S10, (c) P80S20, (d) P70S30, and (e) P60S40

Qualitatively the images which have been obtained on the different selected materials are demonstrated in Figures 3 a $-\mathrm{e}$.

The nanocomposites samples have been rotated at $45^{\circ}$.This include bi-dimensional reconstructed grey level tomographic slices for each material. One can see from these images that the internal structure of the materials can clearly be imaged at various scales thanks to the strong difference in the attenuation coefficient between the solid and the gaseous phase. The black areas indicated the nanocomposites porosity while the white areas are silica particle. The phenolic resins have shown in grey area on the nanocomposites. These 3D images are obtained by drawing a surface between all the voxels exhibiting a same grey level. If this grey level is chosen as belonging to the limit between the solid and gaseous phase, the voxels belonging to the gaseous phase being transparent. The structure is clearly visible in 3D. Figure 4 a shows the Scanning Electron Microscope (SEM) micrograph of the phenolic resin composites samples and figures 4 b-e shows SEM micrograph of the phenolic resin with addition of the different silica content.

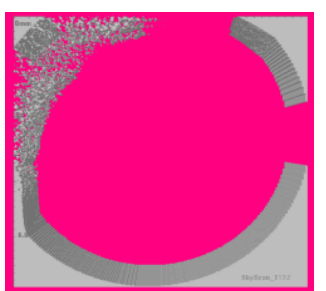

(a)

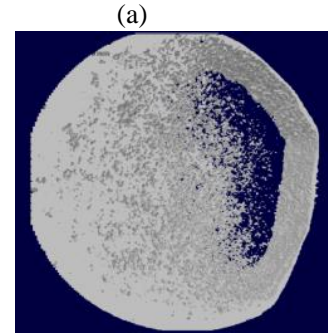

(c)

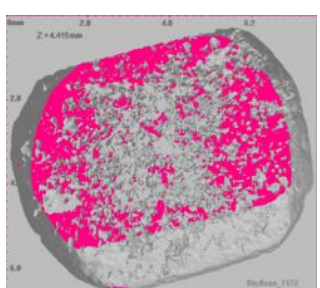

(b)

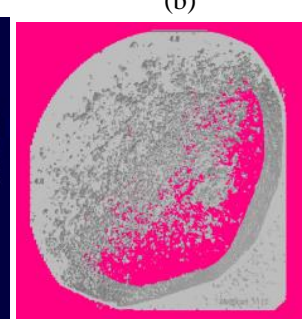

(d)

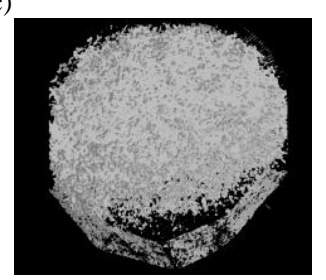

(e)

Fig. 3. The qualitatively the images for nanocomposites sample P70S30 rotated with angel $45^{\circ}$ at vertical side

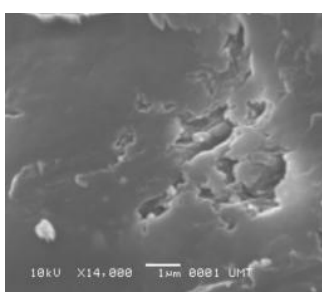

(a)
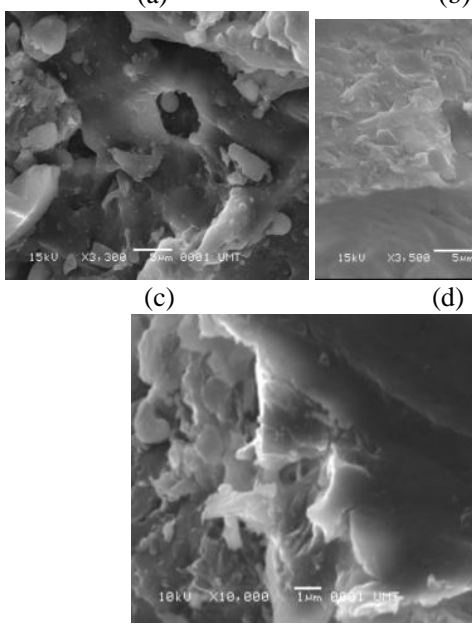

(e)

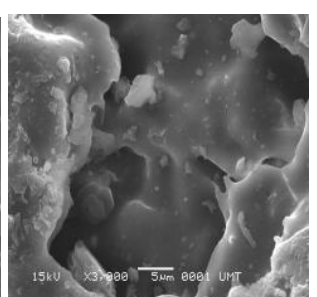

(b)

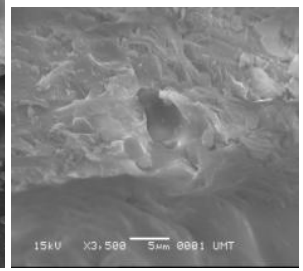

anning Electron Microscope micrograph of the nanocomposites samples (a) P100S0, (b) P90S10, (c) P80S20, (d) P70S30, and (e) P60S40 
The fracture surface with of phenolic resin-silica nanocomposites samples shows quite different morphologies when compared with that of pure phenolic resin composites. Figure 4 a show the SEM images, phenolic resin without addition silica content, fracture surface is relatively smooth and glassy which is typical of a brittle material behavior. The fracture surfaces are of brittle type and a poor adhesion can be seen on the figure. But the Figure 4 b-e phenolic resin addition with silica content fracture surface is not smooth as compare to the unmodified. So that, the phenolic resin-silica nanocomposites less brittle than pure phenolic resin. Figure $4 \mathrm{~b}$ and $4 \mathrm{c}$ shown that the phenolic resin addition with $10 \mathrm{wt} . \%$ and $20 \mathrm{wt} . \%$ of silica content, have many pore than phenolic resin addition with $30 \mathrm{wt} . \%$ and 40wt.\% of silica content.

\section{CONCLUSION}

A phenolic resin-silica nanocomposite is introduced in this study. The improvement of the physical and mechanical properties indicates that the brittleness of the modified phenolic resin-silica composites was decreased than the pure phenolic resin. The observation from the SEM images shows that the pure phenolic resin fracture surface is relatively smooth and glassy which is typical for a brittle material, but the modified phenolic resin fracture surface is rough.

\section{ACKNOWLEDGMENTS}

The authors are grateful to the Terengganu Advanced Technical Institute University College (TATI University College) for financial support of this work.

\section{REFERENCES}

[1] H. Y. Ma, G. S. Wei, and Y. Q. Liu et al., "Effect of Elastomeric Nanoparticles on Properties of Phenolic Resin," Polymer, vol. 46, pp. 10568-10573, 2005.
[2] B. B. Johnsen, A. J. Kinloch, R. D. Mohammed, A. C. Taylor, and S. Sprenger, "Toughening Mechanisms of Nanoparticle-Modified Epoxy Polymers," Polymer, vol. 48, pp. 530-541, 2007.

[3] S. C. Tjong, "Structural and Mechanical Properties of Polymer Nanocomposites," Material Science and Engineering, vol. 5, pp. 73197, 2006.

[4] Q. F. Wang and W. F. Shi, "Kinetics Study of Thermal Decomposition of Epoxy Resins Containing Flame Retardant Component," Polymer Degradation Stability, vol. 91, pp. 1747-1754, 2006.

[5] A. R. Bahramian, M. Kokabi, M. H. N. Famili, and M. H. Behesty, "Ablation and Thermal Degradation Behavior of a Composite Based on Resol Type Phenolic Resin: Process Modeling and Experimental," Polymer, vol. 47, pp. 3661-3673, 2006.

[6] M. C. Chi, L. J. Min, W. C. Chang, and T. H. Ko, "Carbon/Carbon Nanocomposites Derived From Phenolic Resin-Silica Hybrid Ceramers: Microstructure, Physical and Morphological Properties,' Carbon, vol. 40, pp. 977-984, 2002.

[7] S. S. Ray and M. Okamoto, "Polymer/Layered Silicate Nanocomposites: A Review from Preparation to Processing," Polymer Science, vol. 200, no. 28, pp. 1539-1641.

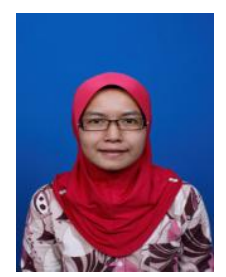

M. Z. Norul Azlin received her first Degree of Science in Material Physics from Universiti Teknologi Malaysia 2006 and Master of Science in Physics (Material Physics) from University Malaysia Terengganu 2008 She start working at TATI University College as Physics and Material Science lecturer from 2009 until now.

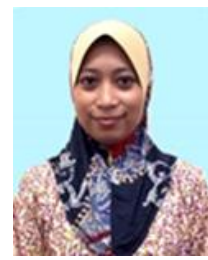

M. Z. Siti Zuraifah received her first Bachelor of Engineering (Computer Aided Design and Manufacture) from University Malaya 2008 and Master of Innovation and Engineering Design from University Putra Malaysia 2011. She start working at TATI University College as Tool and Die Design lecturer from 2009 until now. 